\title{
The role of cell density in the survival of cultured cerebellar granule neurons
}

\author{
Tai-Horng Young, ${ }^{1}$ Jhi-Hsien Huang, ${ }^{1}$ Shih-Hsing Hung, ${ }^{2}$ Jyh-Ping $\mathrm{Hsu}^{2}$ \\ ${ }^{1}$ Institute of Biomedical Engineering, College of Medicine and College of Engineering, National Taiwan University, \\ Taipei, Taiwan, R.O.C. \\ ${ }^{2}$ Department of Chemical Engineering, National Taiwan University, Taipei, Taiwan, R.O.C.
}

Received 27 March 2000; accepted 12 April 2000

\begin{abstract}
The dependence for survival of cerebellar granule neurons on the cell density was examined both experimentally and theoretically. The results of batch experiments revealed that the cell survival index (CSI) was inappreciable, if cell density was below a critical level. If cell density exceeded this critical value, CSI increased with the increase in cell density. In addition, CSI was significantly increased by using a conditioned medium from the dense cultures. This suggests that not only cell density promotes survival of neurons, but also an increased concentration of growth factors produced by neurons has a direct effect on the survival of the neurons. A quantitative model describing the distribution of the growth factor at different cell densities was pro-
\end{abstract}

posed to investigate the role of cell density in the survival of the neurons. We showed the existence of a critical level for cell density, and good agreement in the improvement of CSI was found between the theoretical prediction and the experimental result. Finally, the average concentration of growth factor necessary for cell survival based on our model was in a reasonable range compared to the practice of the addition of neurotrophic factors to the medium of cultured cerebellar granule neurons. (C) 2000 John Wiley \& Sons, Inc. J Biomed Mater Res, 52, 748-753, 2000.

Key words: neurons; cell survival; cell density; growth factor

\section{INTRODUCTION}

The behavior of neuronal cells in a biomaterial has attracted increased attention in recent years because of its scientific interest and clinical importance. ${ }^{1-4}$ Research work in this field has mainly concentrated on attempts to replace lost or dysfunctional neurons following trauma or disease with tissue transplantation or peripheral nerve grafting. ${ }^{4-6}$ In the rat, the development of the cerebellum mainly occurs postnatally. Therefore, the granule neurons can be prepared relatively easily from postnatal rat cerebellum, and these neurons have been extensively used as a model system for neuronal survival and differentiation. ${ }^{7}$ Besides extracellular matrix substrates, other mechanisms such as growth factors and hormones both in vitro and in vivo can affect neuronal survival and the activities of

Correspondence to: Tai-Horng Young, Ph.D., Institute of Biomedical Engineering, College of Medicine, National Taiwan University, Taipei 10016, Taiwan (e-mail: thyoung@ha. mc.ntu.edu.tw)

Contract grant sponsor: National Science Council of Taiwan, R.O.C.

(c) 2000 John Wiley \& Sons, Inc. specific populations of neurons. ${ }^{8}$ Lindholm et al. have shown that the brain-derived neurotrophic factor is a survival factor for cultured cerebellar granule neurons. ${ }^{9}$ Ohga et al. showed that insulin-like growth factor- 1 supported the survival of neurons in culture. ${ }^{10}$

In the present study, we analyzed the effect of cell density on the survival of neurons in culture. Regardless of the effect of substrate, a minimum seeding density of $2.2 \times 10^{5}$ cells $/ \mathrm{cm}^{2}$ was required. In addition, neuronal survival was significantly increased by using conditioned medium from dense cultures. This suggests that at least a certain growth factor secreted by cells acts as a survival factor for neurons in culture. Therefore, not only cell density promotes survival of neurons, but also an increased concentration of the growth factor produced by neurons has a direct effect on survival of the neurons. A quantitative model is proposed, which relates the survival behavior and cell density by describing the distribution of the growth factor.

\section{EXPERIMENTAL}

Commercially available poly (ethylene-co-vinyl alcohol) (EVAL) (105A, Kuraray Co. Ltd., Japan) with an 
average ethylene content of $44 \mathrm{~mol} \%$ was used as the substrate material. The substrate used in the form of a membrane with dense structure was prepared by solvent evaporation in a vacuum oven. ${ }^{11}$ EVAL was chosen because of its use in hemodialysis. In our laboratory, we have prepared EVAL membranes for different biomedical applications such as plasma protein separation and myoblast culture. ${ }^{12,13}$

EVAL membranes were cut into circular discs of 16 $\mathrm{mm}$ diameter, suitably sized for tissue-culture plate wells. The membranes were sterilized with $70 \%$ alcohol under ultraviolet light overnight and then rinsed extensively with phosphate buffer solution (PBS). Subsequently, membranes were placed in 24-well tissue culture polystyrene plates (Corning, NY) by placing a silicon rubber ring on top of each membrane. ${ }^{14}$ Before cell culture, membranes were covered with $10 \mathrm{mg} / \mathrm{L}$ poly-L-lysine (Sigma) in PBS and incubated 2-3 h. The excess poly-L-lysine solution was then removed by suction and dried for $1 \mathrm{~h}$.

Cerebellar granule neurons were prepared from 7-day-old Wistar rats. ${ }^{15}$ Briefly, neurons were dissociated from freshly dissected cerebella by mechanical disruption in the presence of trypsin and DNase. Following preparation, cells in basal Eagle's medium (BME; Gibco) supplemented with 10\% fetal calf serum (FCS; Gibco), $25 \mathrm{mM} \mathrm{KCl}$, penicillin G $(100 \mathrm{IU} / \mathrm{mL})$ and streptomycin $(100 \mu \mathrm{g} / \mathrm{mL})$ were seeded onto EVAL membranes. Cell densities ranging from $0.55 \times$ $10^{5}$ cells $/ \mathrm{cm}^{2}$ to $35.2 \times 10^{5}$ cells $/ \mathrm{cm}^{2}$ were tested for their influence on neuronal survival and development. The cell density was determined by a hemocytometer. Cultures were maintained at $37^{\circ} \mathrm{C}$ in a humidified atmosphere of $95 \%$ air $/ 5 \% \mathrm{CO}_{2}$. One day after plating, the medium was changed and Cytosine arabinoside $(10 \mu \mathrm{M})$ was added to prevent replication of nonneuronal cells. Immunocytochemical analysis of these primary cultures has shown that they contain $95 \%$ granule neurons. ${ }^{16}$

After 5 days of incubation, cell survival was determined by the MTT (3-(4,5-dimethylthiazol-2-yl)-2,5diphenyl tetrazolium bromide, Sigma) colorimetric assay. For the MTT colorimetric assay, the cultures were incubated for $5 \mathrm{~h}$ at $37^{\circ} \mathrm{C}$ with $0.35 \mathrm{~mL}$ of MTT $(0.5$ $\mathrm{mg} / \mathrm{mL}$ in PBS). Mitochondrial dehydrogenases of viable cells cleave selectively to the tetrazolium ring, yielding blue/purple formazan crystals. Therefore, the level of the reduction of MTT into formazan can reflect the level of cell metabolism. After the MTT reaction, the medium was aspirated and the formazan reaction products were dissolved in $0.4 \mathrm{~mL}$ of $10 \%$ sodium dodecyl sulphate (SDS, Sigma) in PBS and the plates were then shaken for $15 \mathrm{~h}$. The optical density of the formazan solution was read on an ELISA plate reader (ELx800, BIO-TEK), at $570 \mathrm{~nm}$. The absorbance was proportional to the number of living cells present. In this work, the cell survival index was expressed as
MTT colorimetric assay/plated cells multiplied by $10^{7}$. Values are means \pm SEM $(n=6)$. Statistical analyses were performed using Student's $t$-test.

\section{RESULTS}

Cerebellar granule neurons were cultured on EVAL membranes for 5 days to study cell survival at different cell densities. Cell survive index was higher at higher cell densities, when seeded cell density was less than $8.8 \times 10^{5}$ cells $/ \mathrm{cm}^{2}$, as shown in Fig. 1 . At very lower cell density (less than $1.1 \times 10^{5}$ cells $/ \mathrm{cm}^{2}$ ), almost no neurons survived. The cell survival index increased from $0.99 \pm 0.02$ at low density $\left(2.2 \times 10^{5}\right.$ cells $\left./ \mathrm{cm}^{2}\right)$ to $2.41 \pm 0.09$ at high density $\left(8.8 \times 10^{5}\right.$ cells $/ \mathrm{cm}^{2}$ ). These data suggest that cell density promotes neuronal survival. Moreover, optical microscope observation confirmed that neuron culture at higher cell density enriches for differentiated neuronal cells. Figure 2 shows that the morphological differentiation of cells was observed when neurons were seeded at different cell densities. At an initial density of $2.2 \times 10^{5}$ cells $/ \mathrm{cm}^{2}$, only scattered cells were present and sparse process development occurred, which were short and did not connect to another cell. In contrast, cells exhibited extensive process development at high cell density $\left(8.8 \times 10^{5}\right.$ cells $\left./ \mathrm{cm}^{2}\right)$. Cellular aggregates contained processes and were connected to another aggregate. Thus, these processes formed a weblike interconnecting network. Cells cultured at cell density of $4.4 \times 10^{5}$ cells $/ \mathrm{cm}^{2}$ exhibited moderate process development.

Based on the above results, an approximately minimum density of $2.2 \times 10^{5}$ cells $/ \mathrm{cm}^{2}$ was required for neurons to survive and to initiate cellular differentiation. Cellular behavior is generally influenced by specific interactions among cell surface receptors and binding sites on the substrate. However, neuronal

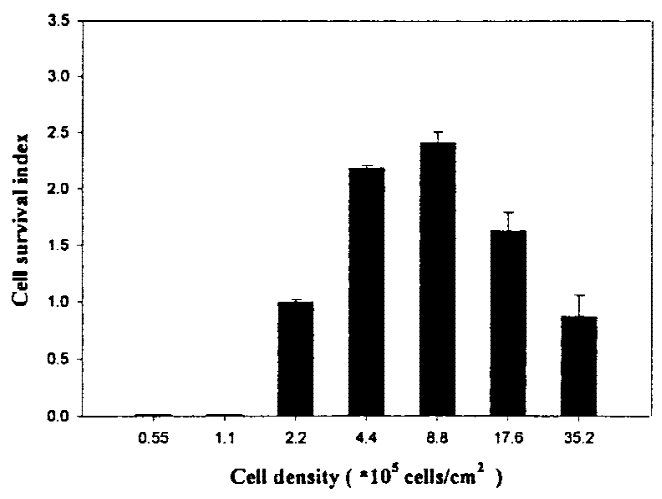

Figure 1. Survival of cerebellar granule neurons plated for five days at different cell densities. Cell survival index was expressed as (MTT colorimetric assay $\times 10^{7} /$ originally plated cells). Values are means $\pm \operatorname{SEM}(n=6)$. 


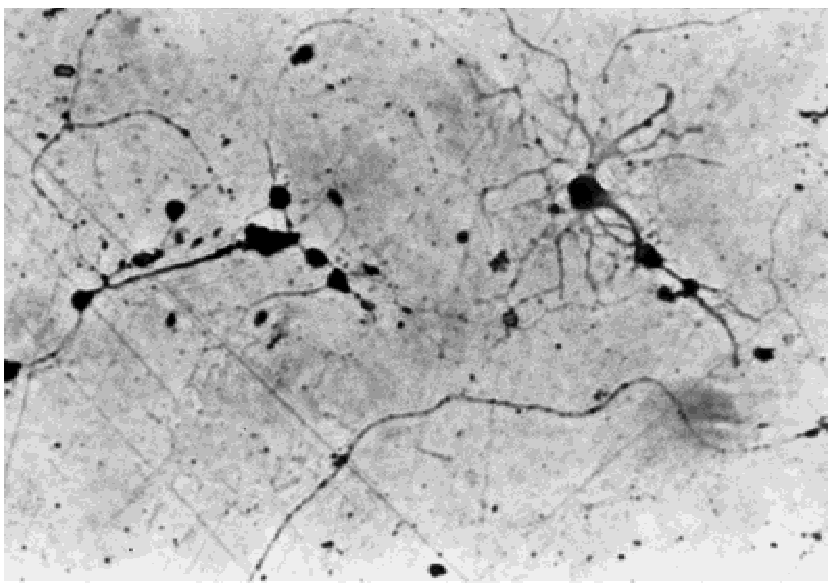

(a)

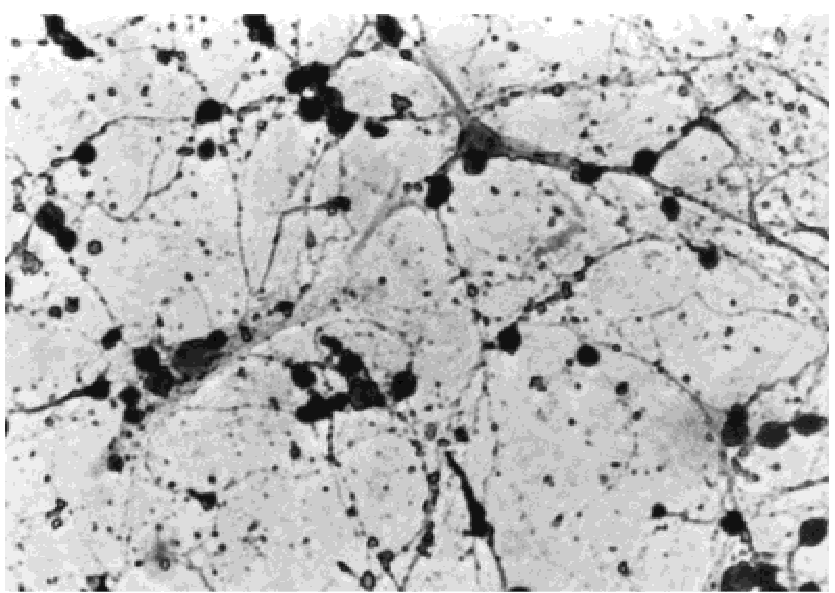

(b)

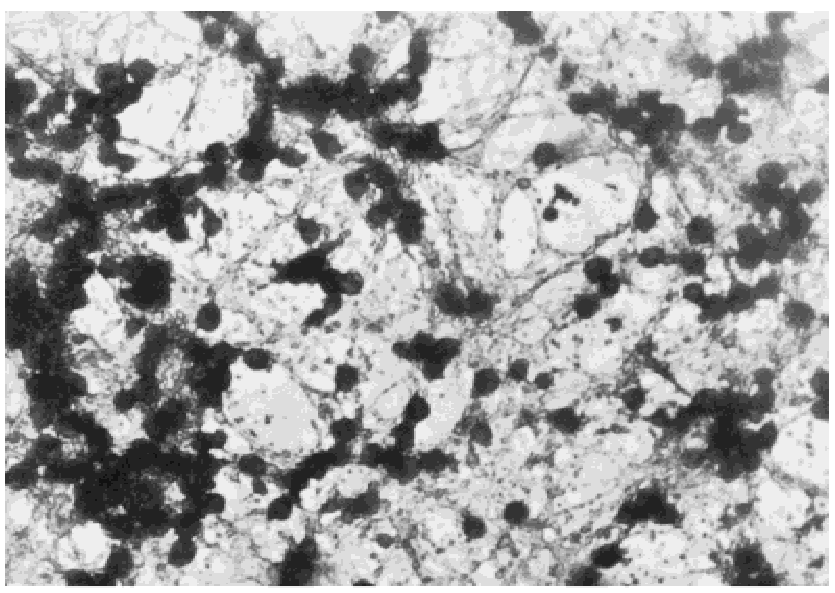

(c)

Figure 2. Photomicrographs of cerebellar granule neurons seeded onto the EVAL membrane at different cell densities after 5 days in culture (original magnification $\times 400$ ). (a) $2.2 \times 10^{5}$ cells $/ \mathrm{cm}^{2}$, (b) $4.4 \times 10^{5}$ cells $/ \mathrm{cm}^{2}$, and (c) $8.8 \times 10^{5}$ cells $/ \mathrm{cm}^{2}$.

cells cultured on glass and EVAL with or without poly-L-lysine coating exhibited the same trend (data not shown). The cell survival index increased with increasing cell density, when the cell density was above a critical level. Therefore, even though the extent of neuron cell development depended on the substrate, the interaction between substrate and neuron might not have a direct effect on the density-dependent increase in neuronal survival. Consequently, the density-dependent increase in neuronal survival might be due to specific interactions between neuronal cell surface receptors controlled by growth factors secreted by neurons. ${ }^{9}$ To justify this concept, medium from dense cultures $\left(8.8 \times 10^{5}\right.$ cells $\left./ \mathrm{cm}^{2}\right)$ after 5 days of incubation was added to a fresh medium for low density cultures $\left(2.2 \times 10^{5}\right.$ cells $\left./ \mathrm{cm}^{2}\right)$. The composition of conditioned medium from dense cultures and fresh medium was a 1:3 ratio. Therefore, the conditioned medium contained higher concentrations of growth factors than a fresh medium. Figure 3 shows that the conditioned medium significantly promoted the survival index of neurons at low density $\left(2.2 \times 10^{5}\right.$ cells / $\mathrm{cm}^{2}$ ) after 5 days of incubation $(p<0.01)$. The cell survival index increased from $0.99 \pm 0.02$ using fresh medium to $2.0 \pm 0.03$ using conditioned medium, only slightly less than that in the $4.4 \times 10^{5}$ cells $/ \mathrm{cm}^{2}$ of cultures using fresh medium. This clearly indicates that not only cell density promotes neuronal survival, but also medium composition has a direct effect on the granule neurons. Thus, the density-dependent increase in neuronal survival could be indirectly due to an increased concentration of growth factors produced by neurons. Growth factors may be certain neurotrophic compounds like brain-derived neurotrophic factors or multiple neurotrophic factors overlapping in the neuronal activities. ${ }^{9}$ Overall, this result raised a possibility that cell-cell interaction by secreted growth factors may act in an autocrine or paracrine fashion in promoting survival of granule neurons. Thus, the low levels of secreted growth factors by the low density of cells had no effect on the neuronal survival in sparse cultures.

Furthermore, if cell density exceeds a certain level

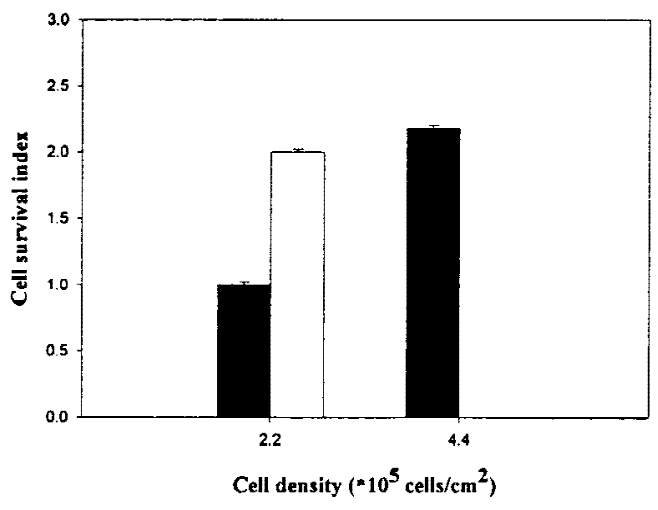

Figure 3. Survival index of cerebellar granule neurons plated for five days using different medium at different densities; ( $\square$ ) fresh medium and $(\square)$ conditioned medium. Values are means \pm SEM $(n=6)$. 
$\left(\geq 8.8 \times 10^{5}\right.$ cells $\left./ \mathrm{cm}^{2}\right)$, cell survival index starts to decrease. As seen in Fig. 1, the very high dense cultures exhibit a decrease of their cell survival indexes by about $32 \%$ at $17.6 \times 10^{5}$ cells $/ \mathrm{cm}^{2}$ and by about $63 \%$ at $35.2 \times 10^{5}$ cells $/ \mathrm{cm}^{2}$ relative to that at $8.8 \times 10^{5}$ cells $/ \mathrm{cm}^{2}$. Although the secreted growth factors are higher at higher cell density, cell densities that are too high lead to rapid depletion of nutrients from the medium, and also give rise to a high concentration of proteolytic enzymes and excitotoxic amino acids derived from dead cells. For example, glutamate is the endogeneous excitatory transmitter used by neurons. ${ }^{17}$ Thus, an excess stimulation of glutamate receptors might be involved in the decline in neuronal cell number occurring in these cultures. ${ }^{18}$ Consequently, either of the above two possibilities could contribute to increased cell death, which results in a poor cell survival index. Therefore, if a conditioned medium was from dense cultures only (without the addition of fresh medium), we did not increase the cell survival index when cells were seeded at a density of $2.2 \times 10^{5}$ cells $/ \mathrm{cm}^{2}$.

\section{Mathematical model}

To elaborate the dependence of neuronal survival on cell density quantitatively, a mass transfer model is proposed. Suppose that the growth of neuronal cells is controlled by one or several growth factors, that is, the growth of cells occurs only if the concentration of these growth factors exceeds a critical level. For simplicity, only the behavior of a representative growth factor is considered in the subsequent analysis. The analysis can be extended to the case of multiple growth factors without too much difficulty. We assume that cerebellar granule neurons are capable of secreting the growth factor, and the growth factor at the cell surface diffuses toward the bulk liquid phase driven by the concentration gradient established near the surface. Apparently, the concentration of the growth factor near a neuron is dependent upon cell density; the higher the density, the higher its concentration. The phenomenon under consideration is simulated in Fig. 4. Here, we consider two adjacent cells each with radius $R$. Let $L$ be the center-to-center distance between two cells and $C$ be the concentration of the growth factor. At steady state, the spatial variation in the concentration of the growth factor is governed by

$$
\nabla^{2} \mathrm{C}=0 .
$$

Let $C_{b}$ be the concentration of growth factor far away from substrate surface and $C_{s}$ be the average concentration of growth factor in a cell. Suppose that the surface of the substrate is impenetrable to the growth

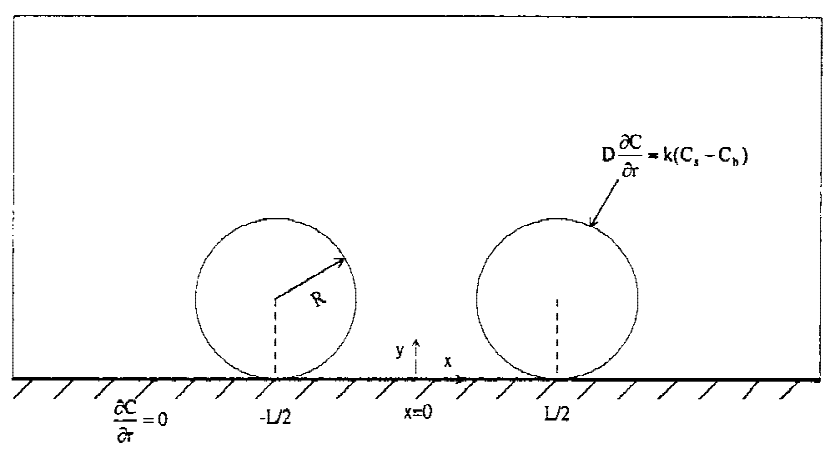

Figure 4. Schematic representation of the model considered. $R$ is the radius of a cell; $L$ is the center-to-center distance between two cells; $n$ is the normal of cell surface; $C$ is the concentration of growth factor; $C_{s}$ and $C_{b}$ are, respectively, the value of $C$ at cell surface and in the bulk phase; $D$ and $k$ are the diffusivity and the mass transfer coefficient of growth factor, respectively.

factor and the rate of transfer of the growth factor at the neuron surface is proportional to the concentration difference $\left(C_{s}-C_{b}\right) .{ }^{19}$ Then the boundary conditions associated with Eq. (1) are

$$
\begin{gathered}
C=C_{b} \text { as } \sqrt{x^{2}+y^{2}} \rightarrow \infty \\
\partial C / \partial y=0 \text { at } y=0 \\
-D \frac{\partial C}{\partial r}=k\left(C_{s}-C_{b}\right) \text { at cell surface. }
\end{gathered}
$$

In these expressions $D$ and $k$ are, respectively, the diffusivity of growth factor and its mass transfer coefficient, and $r$ is the radial distance from the center of a cell. For a simpler mathematical treatment, Eqs. (1)-(4) are rewritten in a scaled form by defining $C^{\prime}=$ $\left(C-C_{b}\right) /\left(C_{s}-C_{b}\right), r^{\prime}=r / R, x^{\prime}=x / R$, and $y^{\prime}=y / R$. We have

$$
\begin{gathered}
\nabla^{2} C^{\prime}=0 \\
C^{\prime} \cong 0 \text { as } \sqrt{x^{\prime 2}+y^{\prime 2}} \rightarrow \infty \\
\partial C^{\prime} / \partial y^{\prime}=0 \text { at } y^{\prime}=0 \\
-\frac{\partial C^{\prime}}{\partial r^{\prime}}=\frac{R k}{D} \text { at cell surface. }
\end{gathered}
$$

The scaled spatial variation in the concentration of the growth factor can be determined by solving Eq. (5) subject to Eqs. (6)-(8). Here, a numerical scheme based on PDEase is chosen.

Figure 5 shows the simulated contours for the spatial variation in the scaled concentration of growth factor. Due to the symmetric nature of the system under consideration, only the right-half contours are presented. The value of $L^{\prime}(=L / R)$ is based on the cell density of $4.4 \times 10^{5}$ cells $/ \mathrm{cm}^{2}$ and $R=2.5 \mu \mathrm{m}$. Figure 5 reveals that the concentration of growth factor decreases with the distance from cell surface, as ex- 


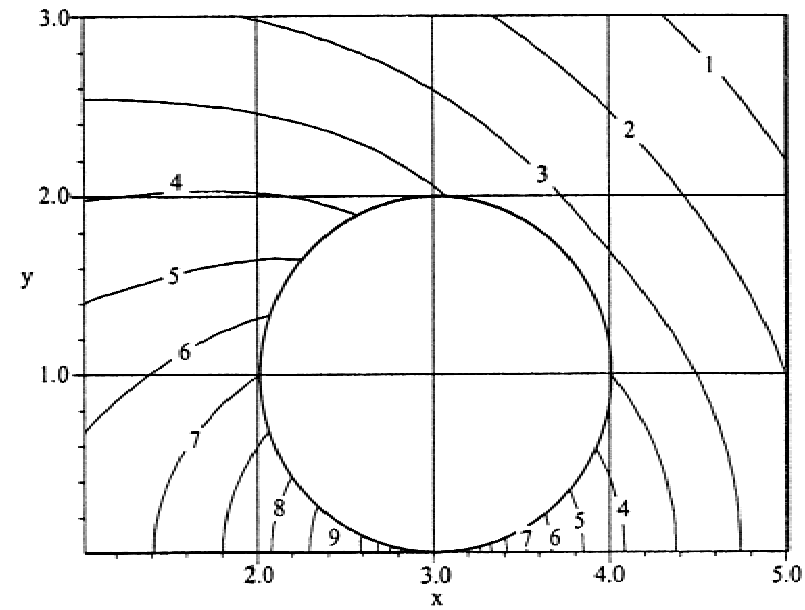

Figure 5. Contours for the spatial variation in the scaled concentration of growth factor. Parameters used are $R=2.5$ $\mu \mathrm{m}, L^{\prime}=L / R=6.03$, and $R k / D=1$ (Bird et al., 1960). Curves $1, C^{\prime}=6.0 ; 2, C^{\prime}=6.5 ; 3, C^{\prime}=7.0 ; 4, C^{\prime}=8.0 ; 5, C^{\prime}=8.5 ; 6$, $C^{\prime}=9.0 ; 7, C^{\prime}=9.5 ; 8, C^{\prime}=10.5 ; 9, C^{\prime}=11$.

pected. However, the growth factor accumulates between cells to create a higher level. It is reasonable to suggest that such an increased concentration of growth factor is beneficial for cells to survive. In addition, since the cell receptors specifically recognize and bind the proteins adsorbed by the substrate to mediate cell behavior, growth factors residing in the culture medium between the cell and the substrate play an important role. As shown in Fig. 5, growth factors between the cell and the substrate are richly distributed, which suggests a condition favorable for cell survival. Hence, the density-dependent increase in neuron survival may be related to the variation of the concentration of growth factors between cells, but less related to the substrate used.

Suppose that a necessary condition for cells to survive is that the concentration of the growth factor needs to exceed a critical level. It can be inferred that the higher the cell density, the shorter the mean distance between two adjacent cells, and the higher the concentration of growth factor between cells. This implies that the higher the cell density, the easier for cells to survive. For simplicity, the level of growth factor at the midpoint of the line segment joining the centers of two adjacent cells, $C_{c}^{\prime}$, is chosen as a measure for the average concentration of the growth factor between two cells. The variation in cell survival index as a function of $C_{c}^{\prime}$ is illustrated in Fig. 6. According to this figure, the critical level for $C_{c}^{\prime}$ is about 7 , that is, to achieve an acceptable degree of survival, $C_{c}^{\prime}$ must exceed 7. The dependence of cell survival index on $C_{c}^{\prime}$ can also be justified by varying the level of growth factor in culture medium. As described in the last section, a conditioned medium comprised $25 \%$ of medium from dense cultures $\left(8.8 \times 10^{5}\right.$ cells $\left./ \mathrm{cm}^{2}\right)$ and $75 \%$ of fresh medium was used to culture neurons at

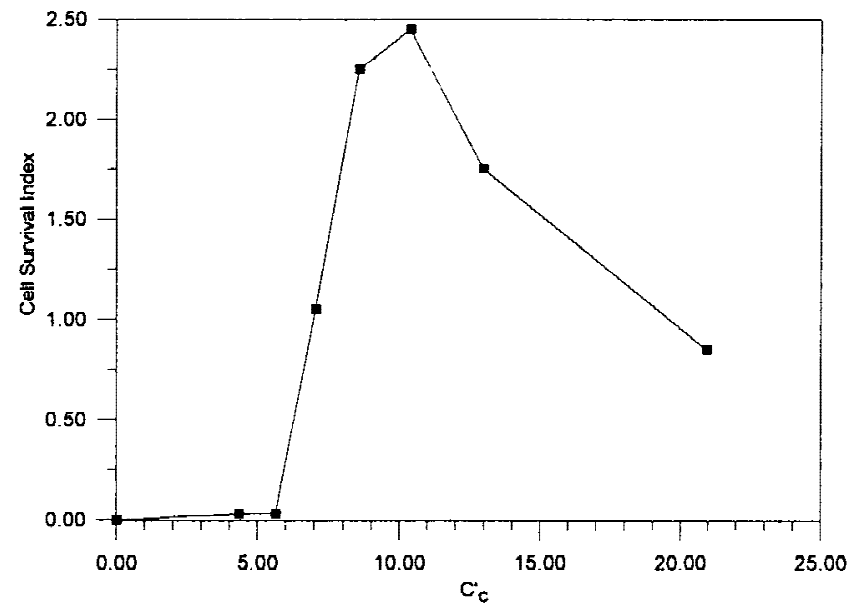

Figure 6. Variation of the cell survival index as a function of the scaled concentration of growth factor at the midpoint of the line segment joining the centers of two cells, $C_{c}^{\prime}$ for the case $R=2.5 \mu \mathrm{m}$ and $R k / D=1 .^{19}$

cell density of $2.2 \times 10^{5}$ cells $/ \mathrm{cm}^{2}$. After 5 days of incubation, the $C_{c}^{\prime}$ value of the conditioned medium is about 7.86, based on the mass balance principle, and the cell survival index is about 2 according to Fig. 6, which is very close to the experimental result (Fig. 3).

Furthermore, the number of receptors on the cell surface is on the order of $10^{4}$ to $10^{5}$ no./cell. ${ }^{9,20}$ Suppose that each receptor is capable of receiving one molecule of growth factor. If the radius of a cell is 2.5 $\mu \mathrm{m}$, then the concentration of growth factor at the cell surface is on the order of $10^{-7}-10^{-6} \mathrm{M}$, which can be considered as the concentration order of the growth factor in a cell. This implies that the average concentration of growth factor necessary for cell survival, based on $C_{c}^{\prime}=7$, is about on the order of $10^{-6}-10^{-5} \mathrm{M}$, a reasonable range in practice with the addition of neurotrophic factors to the culture medium. ${ }^{9,10}$

In summary, the role of cell density in the survival of cultured cerebellar granule neurons is examined both experimentally and theoretically. We show that a positive correlation exists between cell density and cell survival through the growth factor secreted by neurons.

The authors thank the National Science Council of Taiwan, the Republic of China for their financial support of this research.

\section{References}

1. Yavin E, Yavin Z. Attachment and culture of dissociated cells from rat embryo hemispheres on poly-lysine coated surfaces. J Cell Biol 1974;62:540-546.

2. Cabonetto ST, Gruver MM, Turner DC. Nerve fiber growth on defined hydrogel substrates. Sci 1982;216:897-899.

3. Ruegg UT, Hefti F. Growth of dissociated neurons in culture 
dishes coated with synthetic polymeric amines. Neurosci Lett 1984;49:319-324.

4. Schugens C, Grandfils C, Jerome R, Teyssie P, Delree P, Martin D, Malgrange B, Moonen G. Preparation of a macroporous biodegradable polylactide implant for neuronal transplantation. J Biomed Mater Res 1995;29:1349-1362.

5. Aebischer P, Valentini RF, Dario P, Domenici C, Galletti PM. Piezoelectric guidance channels enhance regeneration in the mouse sciatic nerve after axotomy. Brain Res 1987;436:165-168.

6. Langone F, Lora S, Veronese FM, Caliceti P, Parnigotto PP, Valenti F, Palma G. Peripheral nerve repair using a poly (organo)-phosphazene tubular prosthesis. Biomater 1995;16:347353.

7. Burgoyne RD, Cambray-Deakin MA. The cellular neurobiology of neuronal development: the cerebellar granule cell. Brain Res Rev 1988;13:77-101.

8. Snider WD. Functions of the neurotrophins during nervous system development: what the knockouts are teaching us. 1994;77:627-638.

9. Lindholm D, Dechant G, Heisenberg CP, Thoenen H. Brainderived neurotrophic factor is a survival factor for cultured rat cerebellar granule neurons and protects them against glutamate-induced neurotoxicity. Eur J Neurosci 1993;5:1455-1464.

10. Ohga Y, Zirrgiebel U, Hamner S, Michaelidis TM, Cooper J, Thoenen H, Lindholm D. Cell density increases bcl-2 and bcl-x expression in addition to survival of cultured cerebellar granule neurons. Neurosci 1996;73:913-917.

11. Young TH, Lin DT, Chen LY, Huang YH, Chiu WY. Membranes with a particulate morphology prepared by a dry-wet casting process. Polymer 1999;40:5257-5264.

12. Lin DT, Cheng LP, Kang YJ, Chen LW, Young TH. Effects of precipitation conditions on the membrane morphology and permeation characteristics. J Membrane Sci 1998;140:185194.

13. Young $\mathrm{TH}$, Yao $\mathrm{CH}$, Sun JS, Lai $\mathrm{CP}$, Chen LW. The effect of morphology variety of EVAL membranes on the behavior of myoblasts in vitro. Biomater 1998;19:717-724.

14. DeFife KM, Yun JK, Azeez A, Stack S, Ishihara K, Nakabayashi N, Colton E, Anderson JM. Adhesion and cytokine production by monocyte on poly (2-methacryloyloxyethyl phosphorylcholine-co-alkyl methacrylate)-coated polymers. J Biomed Mater Res 1995;29:431-439.

15. Levi G, Alois F, Ciotti MT, Vallo V. Autoradiographic localization and depolarization-induced release of acidic amino acids in differentiating cerebellar granule cell cultures. Brain Res 1984;290:77-86.

16. Thangnipon W, Kingsbury A, Webb M, Balazs R. Observations on rat cerebellar cells in vitro: influence of substratum, potassium concentration and relationship between neurons and astrocytes. Dev Brain Res 1993;11:177-189.

17. Somogyi P, Halasy K, Somogyi J, Storm-Mathisen J, Ottersen OP. Quantification of immunogold labeling reveals enrichment of glutamate in mossy and parallel fibre terminal in cat cerebellum. Neurosci 1986;19:1045-1050.

18. Favaron M, Manev H, Alho H, Bertolino M, Ferret B, Guidotti A, Costa E. Gangliosides prevent glutamate and kainate neurotoxicity in primary neuronal cultures of neonatal rat cerebellum and cortex. Proc Natl Acad Sci 1988;85:7351-7355.

19. Bird RB, Stewart WE, Lightfoot EN. Transport phenomena. New York: Wiley; 1960.

20. Rodriguez-Tebar A, Dechant G, Gotz R, Barde YH. Binding of neutrophin-3 to its neuronal receptors with nerve growth factor and brain-derived neurotrophic factor. EMBO J 1992;11: 917-922. 